\title{
Mining Writing Center Data for Information Literacy Practices
}

\author{
Stephanie J. Graves, Kathy Christie Anders, Valerie Balester
}

\section{Abstract}

- Purpose

- Collaborations between writing centers and libraries create opportunities for providing information literacy intervention for students doing researched writing. This case study gathered data from writing center logs to uncover if and how information literacy activity was occurring during consultations.

- Methodology

- A representative sample of writing center logs recorded between September of 2013 and May 2014 were mined for frequencies of library and information literacy terms. Transaction logs were coded and analyzed according to the frames in the ACRL Framework for Information Literacy for Higher Education.

- Findings

- Information literacy is discussed in only $13 \%$ of consultations. Referrals to librarians accounted for less than $1 \%$ of all transactions. Students most commonly asked for assistance in formatting citations, but deeper information literacy conversations did occur that provide opportunities for engagement with the Framework for Information Literacy for Higher Education.

- Research limitations/implications

- Transactions were examined from one university. Although findings cannot be generalized, the results were applicable to local services, and this study provides a model useful for libraries and writing centers.

- Practical implications

- This study provides ample direction for future collaborations that will take advantage of the intersections of information literacy and writing instruction to improve student research skills.

- Originality/value

- While much has been written about partnerships between libraries and writing centers, this study uniquely demonstrates a model for data sharing across institutional boundaries and how one library mined existing data from a writing center. 


\section{Keywords}

Information literacy, writing centers, collaboration, data sharing, framework, academic libraries, composition, reference, instruction

\section{Article Classification}

Case Study

\section{Citation and DOI for Official Publication:}

Graves, S. J., Anders, K. A., \& Balester, V. (2017), "Mining writing center data for information literacy practices", Reference Services Review, Vol. 45 No. 1, pp. 100-116.

https://doi.org/10.1108/RSR-07-2016-0043

\section{Introduction}

Writing centers and libraries are key strategic partners. Libraries typically help students with research strategies, while writing centers assist with the process of writing. However, these activities are not entirely separate. Good research and writing both require rhetorical knowledge and critical thinking in order to find, read, evaluate, synthesize, and document sources. At colleges and universities, the research and writing processes are often intertwined within the curriculum: students doing research are frequently engaged in writing projects. This case study presents a transcript analysis and coding project undertaken through a partnership between the Texas A\&M University Writing Center and the University Libraries. Both units are seeking to better understand how students use their services in the production of academic research papers or other researched writing such as articles, dissertations, or theses, as well as in posters or slide presentations. Increased understanding in the use of each of the respective services will create meaningful collaborations and improved models of service.

The Texas A\&M University Libraries and University Writing Center have a history of ad hoc partnerships. Similar to many academic universities, one of the primary points of intersection is facilities. The University Writing Center occupies space in two campus library buildings. The central Writing Center office is housed in the main library building. An additional branch location is located in the West Campus (Business) Library. However, there is no Information Commons model in the University Libraries. Library reference services are co-located with a Circulation desk at the front entrance of both library buildings, while the Writing Center is housed on the 2nd floor. Additionally, the Writing Center and University Libraries have different reporting lines. The University Libraries is considered an academic college, reporting up through the University Provost through the Dean of Libraries. The University Writing Center is affiliated with the campus Undergraduate Studies program reporting to the University Provost through the Associate Provost for Undergraduate Studies. The two units do not have shared meetings, strategic plans, or program models. However, as student-centered campus resources, librarians and Writing Center staff often are at the same campus events and orientation programming. The Writing Center is invited to participate in the University Libraries' annual 
Open House and the Writing Center commonly asks a librarian to conduct an instruction session with their consultants at the start of each semester. Both units have also started collaborating on creating workshops and retreats for graduate student research and writing.

An upcoming Library renovation project prompted the Writing Center and University Libraries to think critically about new service models. The Writing Center will be expanded, but will remain in its current location on the 2nd floor. While the Libraries' service desk will remain on the 1st floor, librarians also were presented with the possibility of creating a reference services desk on the 2nd floor, which could be adjacent to the Writing Center. This new opportunity opened up a dialogue about what services the University Libraries provides, what the Writing Center offers, and how the two units have differences and commonalities in service models. As the two units have been operating independently of one another for nearly two decades, many questions were raised about redundancies in services and quality of training. There were also questions about referrals or lack thereof, and which unit "owned" specific content knowledge, such as plagiarism interventions and citation assistance. Members of both units were interested in exploring a data-driven analysis to unpack some of these issues and find avenues for collaborations.

Working together, two librarians in the Learning and Outreach Unit of the Texas A\&M University Libraries and the Executive Director of the University Writing Center formed a research team. Beginning with an analysis of Writing Center data, the research team wanted to explore if and how information literacy and research skills were being addressed during Writing Center interactions. Fortunately, the Writing Center keeps detailed logs about each interaction conducted with students. By data-mining these logs, the authors hoped to uncover areas of commonality in the help students are seeking during the process of writing and researching academic papers. The following five research questions were identified.

- Q1: Are students who visit the Writing Center asking consultants to help with research or information literacy skills?

- Q2: How often are Writing Center consultants referring students to a librarian or library resources?

- Q3: How often did library related key terms appear in the consultant logs? Which terms were most prevalent?

- Q4: Are students early in their academic careers, such as first year students, more likely to seek information literacy help during writing consultations?

- Q5: What types of information literacy and library questions appear in the Writing Center consultation logs?

By addressing these questions, this study hopes to gain a baseline analysis for information literacy interventions within the University Writing Center. Data will allow both librarians and Writing Center consultants see where services to students during the research and writing process may be lacking. It may also help gauge demand for services. If there is a lack of demand for services, this study may illustrate where further efforts at education or outreach could improve demand. Data analysis may also aid in the improvement of services through 
more effective referrals. Additionally, areas for cross-training could be uncovered that would enable both librarians and writing center consultants to answer student questions more effectively. Improving a shared understanding of student research and writing, libraries and writing centers can work creatively to enhance services that match student needs for interventions, skill building, and opportunities for deeper learning.

\section{Literature Review}

Over the past decade, partnerships between university libraries and writing centers have become increasingly commonplace, as evidenced by numerous articles and case studies. Academic libraries have been moving towards service models that include an information or learning commons. Information commons often include services for research assistance, writing assistance, technical assistance, and even tutoring, all incorporated into a singular physical location. Bringing disparate services together into a cohesive geographic location indicates an understanding that many of these service units provide unique expertise that all contribute to a holistic picture of student success. It is not surprising that libraries and writing centers are leading these collaborative efforts; both organizations provide services that help student attain their academic goals, from researched writing (Cooke \& Bledsoe 2008) to completing courses, and thus the collaboration can lead to referrals between writing centers and libraries (Mahaffy 2008).

Collaborations between libraries and writing centers take many forms, but regardless of their shape, such collaborations tend to focus on building student skills for academic success. Some examples of current library/writing center partnerships include joint meetings between staff, sharing space, embedding librarians into writing centers, teaching workshops together, and providing information literacy instruction to writing center consultants (Ferer 2012). While recognizing that these types of collaborations may appear "daunting" to initiate, Zauha notes that it is important to develop relationships lest libraries "[miss] an opportunity to explore information literacy as a conversation rather than lesson or turf" $(2014$, p. 5). The proliferation of collaborative projects points towards a growing student-centric model of academic help services. Participating units, including libraries, must reconsider traditional ideas about owning particular services and be willing to blur conventional lines between academic units.

As new partnerships have developed, so too have new service models that blend the best practices of writing and research assistance. Library collaborations within writing centers can enhance the depth and quality of the research advice provided. Using ethnographic interviews with second-year students, librarians at Rollins College investigated the intersections between the recursive process of student research and writing. Extending beyond the co-location of service points, their findings led to the creation of a peer-to-peer research service (Montgomery 2015). The University of Denver's Penrose Library developed a Research Center, structured similarly to a writing center (Meyer, Forbes \& Bowers 2010). At the university level, deep collaborations can lead transformational change, such as aligning service models with university Quality Enhancement Plans (Gardner, Napier \& Carpenter 2014), although such change can be 
difficult in the face of complex and unequal power structures (Solberg 2011). However, there are also examples of successful collaborations between writing center consultants, librarians, and writing instructors, who can work together to create more meaningful and better-integrated instruction (Pagnac et al. 2014).

Indeed, the time is ripe for larger discussions about how information literacy intersects with other disciplines. As the Framework for Information Literacy for Higher Education states, "... it is based on a cluster of interconnected core concepts, with flexible options for implementation, rather than on a set of standards or learning outcomes, or any prescriptive enumeration of skills" (2015). This flexibility makes it much easier to see how information literacy can be integrated throughout various disciplines, including writing. The intersection between information literacy and writing is becoming particularly relevant as scholarship is emerging about how the Framework for Information Literacy for Higher Education relates to the Framework for Success in Postsecondary Writing, developed jointly by the Council of Writing Program Administrators, the National Council of Teachers of English, and the National Writing Project. Not only is this discussion timely, but it represents a real move forward in the collaborations between librarians and composition instructors, a collaboration that has been suggested for some time now (Birmingham et al. 2008). It is important for librarians to consider the research/writing habits of students as an integrated set of concepts and skills.

Juxtaposing the Framework for Information Literacy for Higher Education with the work of writing centers moves librarians one step closer to a practice that can share a theoretical framework with rhetoric and composition. Such a relationship between information literacy and writing studies has been long called for by authors such as James Elmborg (2005) and Rolf Norgaard (2003), and uniting the two provides opportunities to talk about how information is used, created, and valued. No longer solely about the skills of information literacy, the Framework is more concerned with the individual's relationship with information and the relationship between information and society. As such, the Framework reflects a view that necessarily goes beyond the bounds of "library skills" alone.

Consequently, mapping some aspects of writing center work onto the Framework for Information Literacy for Higher Education is challenging. Information literacy teachers and writing center consultants cannot, and should not, dismiss the "nuts and bolts" of skill-based work, which remain as vital to academic and life-long success as it ever has. However, given that the Framework speaks in terms of dispositions and conversations, it is not clear where some long-standing traditions of bibliographic instruction, such as citation format, cleanly fit in. Certainly, many aspects of the more skill-based Information Literacy Competency Standards for Higher Education are relevant to the work of writing centers and writing instructors, and developing collaborations that can accommodate a variety of perspectives is important.

The current study builds on the existing literature regarding library and writing center partnerships by exploring the intersections of information literacy and writing instruction. This study is unique in its approach, utilizing pre-existing data to uncover what types of information literacy activities are occurring within the Writing Center. Exploring student transactions will 
help determine what types of collaboration will be most fruitful. This data-driven approach can aid in programmatic improvement, help inform training curriculum, and even illuminate a path forward for new shared service models. As noted above, beginning collaborations between writing centers and libraries can be intimidating, but the data-mining approach presented in this study models a low-stakes avenue for embarking on collaborative projects.

\section{Methodology}

The University Writing Center employs undergraduate, graduate, and professional consultants who work one-to-one to aid students in the writing process. Consultations may occur face-toface or online (synchronously or asynchronously). At the conclusion of each consultation, the Writing Center consultant records notes on what was covered during the session in an online transaction log system (see Appendix B). This case study mined the consultant logs with a set of keywords related to research processes, information literacy, and library terminology. Logs from Sept. 1, 2013 through May 1, 2014 (one full academic year) were used to create the data set. Using descriptive statistics, researchers looked for the frequency with which library and research concepts showed up in writing center consultations. As a next step, the researchers performed a textual analysis using a coding scheme that mapped to the ACRL Framework for Information Literacy for Higher Education.

In order to begin the text mining process, the authors developed a list of key terms related to library research and information literacy. These key terms would be used to in order to identify instances in which information literacy interventions occurred during writing center consultations. After an initial brainstorming session, over 85 words were identified as possibilities. Terms included words such as database, research, and search.

Next, the Writing Center Executive Director randomly selected two writing center consultants and ran a beta test against their transaction logs. The frequency with which the key terms appeared were recorded. If a log included key terms, the relevant sentences or paragraphs were recorded for close reading and analysis. The research team met again to review the test data. Some key terms were retracted due to redundancies. For instance, it was determined that the word "find" was unnecessary, as it would always appear in the data with the object of what the student may be looking for in relationship to either sources, databases, services or evidence. The research team also elected to add new key terms, such as data, LibGuides, and guides. During this refinement phase, the team also developed definitions for ambiguous terms that appeared in the test data. For example, the term "article" had specific and clear meaning to the librarians on the research team. Librarians assumed the frequency of the word "article" in transaction logs would indicate a high level of research interaction between writing center consultants and students. Upon a closer reading of the test logs, it was determined that the word "article" was being used frequently by the writing center consultants to identify a grammatical part of speech in the students' writing, e.g. a, an, the. Several of these ambiguous terms appeared in the data. The authors agreed upon definitions for each term so that the Writing Center Director could exclude false hits in the data set. Any unclear results would be included and removed later after review by the research team. 
Once the refinement phase was complete, the research team was ready to begin text mining. The consultation system did not allow for a meta-search across all consultants logs, so the Writing Center Director had to mine the data one writing center consultant at a time. In the study year, there were 11,464 consultations performed by over 50 consultants employed by the Writing Center. While the initial research plan called for a search across all logs, it was determined that this approach would be too time-intensive. The Writing Center Director selected 12 consultants using a random number generator. The random selection of consultants was important to maintaining the anonymity of consultants and helped to control for selection bias based on the research teams' knowledge of and experience with individual consultants. An academic year's worth of logs were mined for each consultant to create a representative sample. The Director proceeded to run the key terms against each of the selected consultants, a process that took many hours. Per institutional guidelines for research involving human subjects, steps were taken to exclude any identifying student information that was present in the data by either redacting names or replacing names with non-identifying lettered initials. Additionally, consultants were assigned a random number rather than identified by name. Care was also taken to store and encrypt data to protect student privacy.

Exported results were combined into a singular document and housed locally on a limited access data drive for textual analysis. Each consultant log was assigned a unique identifier number and frequencies were generated based on the number of uses for each key term. Next, each log was read, discussed, and coded by the two librarians on the research team. Using a spreadsheet, the librarians coded each transaction according to the frames in the Framework for Information Literacy for Higher Education. Each transaction could be coded for as many, or as few, of the frames as applied to the interaction. During coding, the researchers also decided if a particular log did not meet the qualifications for inclusion, i.e. no relationship to information literacy, research, or library skills. All coding was done as a team, so issues of interrater reliability were null.

\section{Results}

\section{The Data Set}

In the study sample, the twelve writing consultants conducted 2,208 consultations. The Writing Center Director flagged 368 logs in which one or more of library key terms were identified. After coding by the librarians, 72 logs were excluded as false-matches. The excluded logs contained a key term that matched the list, but were not relevant to information literacy or research skills typically addresses in library instruction and reference interactions. Examples include students seeking "information" on grammatical parts of speech, referring to "quotes" when thinking about a piece of literature, or lists of "references" for a resume. At the conclusion of coding, 296 valid logs remained in the data set. All subsequent analysis is based on the 296 logs in the data set.

Q1: Are students who visit the Writing Center asking consultants to help with research or information literacy skills? 
Students are asking for information literacy and research assistance during Writing Center consultations, but relatively infrequently. The number of logs in which a Writing Center consultant addressed an issue related to information literacy, library services, or research skills was small compared to the overall total. Only 296 of 2,208 logs were valid matches for library key terms. This accounts for approximately $13 \%$ of Writing Center transactions in the study period, as shown in Table 1.

[insert Table 1]

Table 1

While library key terms appeared infrequently in the transaction logs, the research team was struck by the large distribution in the numbers between individual consultants, ranging between $6 \%$ to $25 \%$. Some consultants had much higher instances of library related terminology in their consultant notes. The identity of the individual consultants was kept anonymous from the librarians authors for purposes ensuring confidentiality and for IRB approval. Therefore, consultant data cannot be analyzed based upon characteristics of the consultants. The differences in usage of library terms should not be ascribed to students coming to the Writing Center, since in the majority of cases, Writing Center consultants are randomly assigned to tutoring appointments. The differences in the data may, however, raise a number of questions about the consultants. Did the Writing Center consultants that discussed library concepts more often have more training? Were students simply more comfortable using library resources and therefore more likely to mention them to students? The Writing Center employs both undergraduate and graduate students as consultants. Were graduate student consultants more likely to mention the library? Future studies which look more closely at consultant training and library skills could uncover the nuances of these questions.

\section{Q2: How often are Writing Center consultants referring students to a librarian or library} resources?

A robust referral model is highly desirable for a successful collaboration between the Libraries and Writing Center. Of 296 interactions in the study that were coded for library and information literacy key terms, a student was only referred to a librarian or library staff member 10 times. Additionally, there were 7 logs in which a consultant referred a student to the library's website, a LibGuide or a library handout. In total, referrals took place in less than $6 \%$ of the interactions. It is worth noting that this $6 \%$ refers to only those interactions included in the data set. When compared to the 2,208 consultations completed by the twelve consultants, library referrals occurred in less than a half of $1 \%$ of the transactions.

Q3: How often did library related key terms appear in the consultant logs? Which terms were most prevalent? 
Word counts show instances of 2,239 uses of key terms in the data set. After the logs were reviewed, the count was reduced to 1,818 uses of library key terms. The reduction in the raw count was done by redacting instances in which the key terms appeared erroneously in the data, such as appearing in a website URL or as a root word (e.g. OWL appears as a root word in knowledge).

Sixty three key terms appeared at least once in the logs, while 22 words never appeared in a single log. Words that commonly appeared included citation, MLA, APA, sources, and research. Key terms that never appeared tended to be specific to library services and jargon such as interlibrary loan, RefWorks, Boolean, call number, Primo, and reserves. The dispersion amongst the key terms is noteworthy, with the term "citation" appearing 303 times, three times as often as any other word in list. The next highest frequency words are "APA" and "find," with 117 and 114 matches. Appendix A shows the raw counts of all 85 key terms.

Q4: Are student early in their academic careers, such as first-year students, more likely to seek information literacy help during writing consultations than more advanced students?

Unlike library reference data, the Writing Center collects demographic data from all students who participate in any consultation appointment. Transaction log data was analyzed based on student year. Table 2 depicts the number of consultation logs by student year compared to the total number of logs that were coded for library and information literacy key terms.

Undergraduate students are identified by their year in school, freshman through senior. The university records the students' year in school based on number of credit hours completed. Graduate students appear in the data in three distinct groups. Post-baccalaureate, non-degree students are taking graduate level courses, but without formal admission to a specific degree program. There are relatively few students in this category at the University. The remaining two graduate level distinctions reflect admissions status in degree programs, masters and doctoral.

Logs containing information literacy concepts remained consistent across undergraduate student level (freshman-senior) and doctoral level at 5\% and 6\% respectively. However, there is an increase in the frequency of information literacy terms in Writing Center consultation logs at the graduate masters and post-baccalaureate levels, around 10\%. Early career students, such as first-year students, were not more likely to seek information literacy help explicitly during Writing Center consultations than master's level students in the study.

The Writing Center provides extensive workshops and programming for graduate students working on their graduate thesis or dissertation. The increase in library key terms may be an indication of the type of involved research that graduate students are undertaking. However, more investigation would be necessary to address any correlation.

[insert Table 2]

Table 2. 
*Note: There were 10 instances of 298 logs in which no student data is recorded. These have been subtracted from the data.

Q5: What types of information literacy and library questions appear in the Writing Center consultation logs?

Librarians coded each transaction log according to the frames of the Framework for Information Literacy for Higher Education. Each transaction could be coded for as many, or as few, of the Frames as applied to the interaction. Early in the coding, it became apparent that citation format was a principal issue in the data set. There were many instances in which a Writing Center consultant was asked to review the "correctness" of APA or MLA citation style. Two of the frames could possibly deal with citation format issues, "Scholarship as Conversation" and "Information has Value." However, coding citation style questions into the Framework for "correctness" of citation format could skew the data considerably. Therefore, when transactions logs only addressed the correctness of citations, a separate code was assigned for "Citation Format." Transactions that dealt with deeper issues such as plagiarism, copyright, and intellectual attribution where given the code for Information has Value. Transactions that included references to scholarly conversations, contextualizing disciplinary knowledge, and literature reviews were coded as Scholarship as Conversation.

Figure 1 shows the distribution of transcripts attributed to each code. "Citation Format" was the most prevalent code, with 230 instances. "Scholarship as Conversation" was the next highest category with 57 logs coded. "Information has Value" follows with 47 instances. Issues regarding authority of sources, or "Authority is Constructed and Contextual," was fourth with 32 codes. "Research as Inquiry" and "Searching as Strategic Exploration" were nearly even, with 26 and 25 instances respectively. With only 8 instances, "Information Creation as Process" was the least used code in the data set.

[insert Figure 1]

Figure 1.

\section{Discussion}

One of the central research questions this study sought to address was to discover if information literacy instruction might be happening in the Writing Center. Not surprisingly, information literacy is being discussed in the context of writing consultations, although only in a relatively small percentage of consultations. In those interactions that did occur, "Citation Format" dominated all other categories, more than all other categories combined. Students were explicit with their concerns about the correctness of citations, both within the text of their writing and in bibliographies. Traditionally, formatting citations is an area that writing centers and 
libraries both own as a part of their practice. While the mere formatting of citations is a low-level concern both in recent iterations of composition theory and information literacy, the results of this study indicated it is still a cause for considerable concern for students. Students may have history with faculty who penalize them for incorrectly formatted citations or fear that faculty will do so. While the high percentage of codes for "Citation Format" is striking in the data, it is also expected for this reason. The high demand for citation format services indicates an area of opportunity for a shared service model between the University Libraries and the University Writing Center.

While the frequency of "Citation Format" codes in the data is unsurprising, it also presents a significant intervention point for information literacy. The authors are far from rejecting the idea that writing centers or libraries should cease to help students learn how to format citations. Instead, practitioners in libraries and writing centers can use the opportunity to expand the conversation with students. Analyzing citation format provides an opportunity to begin a conversation about why writers and researchers provide citations at all, the differences between popular and scholarly sources as evidence for researched writing, and scholarship as a conversation in which students are active participants. Unfortunately, there are no instances in the current study where this appeared to have occurred. Writing Center consultants addressed the issue of citation "correctness" but did not transition the conversation into more conceptual discussions about information literacy.

Writing Center consultants are not formally trained in information literacy concepts, but the intersections between research and writing are undeniable and the opportunities for engagement are immense. The Framework for Information Literacy for Higher Education provides a context for exploring practices that extend beyond citation format. Instead of discussing citation format only as a convention, this topic could be reframed to incorporate the larger ideas of the Framework. Citation is a key component of the interchange of ideas, both because citing provides credit and because it allows a reader to follow a larger conversation. Both ideas are reflected in the Framework, under the "Information has Value" and "Scholarship as Conversation" frames. These two frames also showed up many times in the analysis as areas for interventions, as places to address plagiarism, or to talk about how to integrate outside sources into writing. More importantly, these frames invite researchers to think of themselves as partaking in an information community, in which there are customs concerning the ownership and sharing of information and the discourse of research. The focus on concepts in the Framework suggests that the dispositions and practices will follow from an understanding of the concepts, and these concepts are what can be shared between writing centers and libraries.

Additionally, there are could be practical reasons why consultant logs fail to show more in-depth conversations about information literacy topics. Librarians on the research team were reminded by the Writing Center Director that each consultation appointment is limited in duration to 30-45 minutes; consultants often struggle to complete all the necessary writing assistance in just one appointment and are trained to address student concerns during that time. That is, consultants may be guided by more pressing writing concerns students have expressed and thus miss an opportunity to delve more deeply into instruction on information literacy. Regardless of how 
much information literacy training is provided to Writing Center consultants, there may not be time to teach additional content during an appointment. In addition, students may not be interested in learning it, and writing consultants will not have the depth of knowledge that librarians can bring to motivating them. Therefore, referrals to a librarian could be one option to opening up a continued dialogue with students. Study data indicated very few referrals occurred and the methodology used did not collect data on why consultants chose to refer students to a librarian or not. If consultants received additional information literacy training, would referral to a librarian be more likely? Would students be motivated to attend a referral appointment? Additional research in this area is warranted. Conversations between librarians and the Writing Center are ongoing about how data on referrals can be collected. The issue of referrals is becoming increasingly complex and necessary as the library begins the process of a substantive renovation that will disrupt both the Writing Center location and reference services.

Additionally, this study's text-mining analysis suggests that there are other areas of information literacy that are not currently receiving much attention in the Writing Center. For example, there is an opportunity for consultants to discuss "Information Creation as Process" with students, and it is striking that this frame showed up very little in the analysis. Very rarely did consultants speak with students about how information cycles through different publication cycles or different formats, probably because consultants are not specifically trained on this concept. This is not to say that there is not an opportunity for such a conversation to occur, but this frame is mostly concerned with production and dissemination cycles of information, and this could be a place to talk about information creation from the creator's side. Librarians and Writing Center consultants can work together to highlight that information creation itself is a process, one that involves searching, evaluating, revising, processing, and drafting, and is recursive and iterative. Writing Center consultants have the unique opportunity to help students understand their involvement in information creation and own their role as information authors.

An unexpected result of the analysis was that there are concepts from composition theory that would be helpful to translate between information literacy and composition. Attending to the conventions of genre is a core concept that is taught in writing (Framework for Success in Postsecondary Writing 9), and there is a corresponding concept in information literacy, although it is not usually discussed using the term "genre." Rather, the Framework for Information Literacy for Higher Education uses the term "format" in the "Information Creation as Process" frame. The consultation logs revealed that there were several instances where there was an opening to talk about genres of information, such as abstracts, literature reviews, newspaper articles, journal articles, etc. While librarians often teach others how to separate information into scholarly and non-scholarly categories, and the Framework for Information Literacy for Higher Education speaks of genres of information insofar as different aspects of the publication process entail different formats of information, it could also be helpful to address format in terms of thinking about to use or create those different genres of information oneself. Engaging the student-as-author seems particularly relevant given that a large number of consultations are occurring with graduate students, future scholars in their own right. 
This case study analysis of consultant logs uncovered ample opportunity for librarians to integrate information literacy into Writing Center consultation work. The recursive nature of research and writing lends to natural collaboration between the two groups. Certainly, workshops aimed at improving consultants' research skills and/or librarian's writing skills could be one method for collaboration. However, after analyzing approximately 300 consultant logs, the more meaningful approach seems to lie in a better conceptual understanding of information literacy concepts and their relationship to research writing. The exploration of the Framework, composition theory, and writing center pedagogy can open new dialogues that take a holistic approach to the student doing research writing. By coming to a shared understanding of information literacy that extends beyond research tips and tricks, librarians and consultants can engage in deeper discussions about scholarship as a conversation, both with information and with rhetoric.

\section{Limitations and Further Study}

Results from this case study are limited to a local institution and cannot be generalized across institutions. However, libraries and writing centers can look to this study as a model for data sharing across organizational boundaries. By sharing preexisting data and collaborating to analyze results, both organizations have finished this study with a better understanding of the other and a renewed interest in partnerships to improve student success.

There are particular aspects of this study that have opened paths to further study. Some consultants mentioned library services and research skills far more frequently in their consultation notes than others, and this is a cause for further investigation. One possibility for this disparity is that some consultants were more knowledgeable about information literacy concepts than others. Another possibility is that some consultants are simply more likely to document those parts of their interactions, that some consultants tutor more students, or that some consultants coincidently worked with more students doing research-based writing. However, the individual identities of the randomly selected twelve Writing Center consultants were protected for the sake of anonymity. Therefore, the results did not allow for an analysis of why some consultants were more likely to engage in discussions about information literacy concepts with students. A follow up to this study could include an analysis of Writing Center consultants' knowledge of library services and information literacy concepts. Follow up studies could control for such as consultant knowledge, training, number of consultations, and level of consultations (e.g. undergraduate vs. graduate writing projects). Results could be compared to a textual analysis of consultant logs in order to test a correlation between information literacy training and intersections with writing instruction. However, to really understand what, precisely, is occurring in writing center consultations, it would be preferable to conduct direct observations of these interactions between consultant and student.

Also of interest is the role of faculty and the possible lack of faculty knowledge about writing and research pedagogy. Too often, faculty tell students to "use any citation style" or "limit your research to five sources," or "never use the Internet for research." The results of this study may 
indicate a curricular gap. Students may not be requesting help with research because faculty are not assigning research, are not assigning research that is challenging, or are not emphasizing information literacy in their assignments of research writing. Further studies might include an analysis of student assignments and faculty perceptions of researched writing in their curriculum. Future opportunities might include faculty development workshops and programming.

Additionally, this project data-mined Writing Center consultant notes, providing a one sided view of the intersections of the research/writing enterprise. A similar study could be conducted with library data. While the library does not keep a log of all reference transactions and student data in the same manner as the Writing Center, the library does have a record of transactions in the virtual reference (VR) chat system. The research team is interested in mining VR transcripts for writing-related key terms in order to discover how librarians may be aiding students with writing process. Additionally, comparing the current study with an analysis of library transcripts may further benefit the discussions about collaborative service models, cross-training, and the intersections of research and writing.

\section{Conclusion}

This case study has generated numerous benefits, some of which were unexpected. Certainly, the results of this study's transcript analysis helped illustrate if and how information literacy concepts were being addressed within University Writing Center consultations. While information literacy topics are being addressed in only $13 \%$ of interactions, there are areas for improved engagement and referrals to librarians with students using writing center services. Information gathered will help inform programmatic improvements and training efforts. An unintended result, the librarians and Writing Center staff have become attuned to pedagogical similarities in the respective fields. Applying the Framework for Information Literacy to Writing Center interactions opened the door to frank discussions about the terminology in each field and the conceptual frameworks that inform the work of each service. Librarians and writing center professionals who are looking to explore the adjacencies between information literacy and writing assistance programs can use and adapt the data mining method described in the case study in order to uncover what's occurring in local environments. More importantly, the collaboration that comes from a shared research endeavor can pave the way to deeper and more fruitful relationships between librarians and writing centers.

\section{References}

Association of College and Research Libraries. (2015), Framework for Information Literacy for Higher Education, American Library Association, Chicago. Available from:

http://www.ala.org/acrl/standards/ilframework. [7 July 2016]. 
Cooke, R. and Bledsoe, C. (2008), "Writing centers and libraries: one-stop shopping for better term papers", Reference Librarian, Vol. 49 No. 2, pp. 119-127. Available from:

http://dx.doi.org/10.1080/02763870802101310. [5 May 2016].

Council of Writing Program Administrators, National Council of Teachers of English, and National Writing Project. (2011), Framework for Success in Postsecondary Writing, Council of Writing Program Administrators, National Council of Teachers of English, \& National Writing Project. Available from: http://wpacouncil.org/files/framework-for-success-postsecondarywriting.pdf. [3 March 2016].

Elmborg, J. (2005), "Libraries and writing centers in collaboration: a basis in theory", in Elmborg, J. and Hook, S. (Eds.), Centers for Learning: Writing Centers and Libraries in Collaboration, Association of College and Research Libraries, Chicago, pp. 1-20.

Ferer, E. (2012), "Working together: library and writing center collaboration", Reference Services Review, Vol. 40 No. 4, pp. 543-557. Available from: http://dx.doi.org/10.1108.00907321211277350. [3 March 2016].

Gardner, B., Napier, T. L., and Carpenter, R. G. (2013), "Reinventing library spaces and services: harnessing campus partnerships to initiate and sustain transformational change", Advances In Librarianship, Vol. 37, pp. 135-151. Available from: http://dx.doi.org/10.1108/S0652830(2013)0000037010. [5 March 2016].

Mahaffy, M. (2008), "Exploring common ground: US writing center/library collaboration”, New Library World, Vol. 109 Nos. 3/4, pp. 173-181. Available from: http://dx.doi.org/10.1108/03074800810857621. [4 February 2016].

Meyer, E., Forbes, C., and Bowers, J. (2010), "The research center: creating an environment for interactive research consultations", Reference Services Review, Vol. 38 No. 1, pp. 57-70. Available from: http://dx.doi.org/10.1108/00907321011020725. [22 June 2016].

Montgomery, S.E. and Robertshaw, S.D. (2015) "From co-location to collaboration: working together to improve student learning", Behavioral \& Social Sciences Librarian, Vol. 34 No.2, pp. 55-69, Available from: 10.1080/01639269.2015.1047728.

Norgaard, R. (2003), "Writing information literacy: contributions to a concept", Reference \& User Services Quarterly, Vol. 43 No.2, pp.124-130. Available from: http://www.jstor.org/stable/20864155. [3 February 2016].

Pagnac, S., Boertje, C., Bradfield, S., McMahon, Elizabeth, and Teets, G. (2014), "An embedded model: first-year success in writing and research", Praxis, Vol. 12 No.1, pp. 39-44. Available from: http://www.praxisuwc.com/new-page-1/. [7 July 2016]. 
Solberg, J. (2011), "Becoming learning commons partners: working towards a shared vision and practice", Journal Of Organisational Transformation \& Social Change, Vol. 8 No. 3, pp. 243-260. Available from: http://dx.doi.org/10.1386/jots.8.3.243_1. [14 May 2016].

Zauha, J. (2014), "Peering into the writing center: information literacy as a collaborative conversation", Communications In Information Literacy, Vol. 8 No.1, pp. 1-6. Available from:

http://www.comminfolit.org/index.php?journal=cil\&page=article\&op=view\&path\%5B\%5D=v8i1p1 . [7 July 2016]. 